\title{
Activity of different life spheres and environmental security of students
}

\author{
Svetlana Vasyura*, and Olga Nikitina \\ Udmurt State University, Izhevsk, Russia
}

\begin{abstract}
Rapidly developing information technologies bring to crucial changes in different areas of student life activities - learning, communications, leisure - and have an impact on individuals' activities. Empirical research aims to identify connections of activity and ontological security in communications, knowledge, learning, experiences, reflection. The assumption, that activity in communications and activity in learning have closer links with ontological security than activity in other areas of life, is put forward as a hypothesis. Theoretical basis of the research creates A.A. Volochkov's concept of activity of an individual (subject), N.V. Kopteva's theoretical construct of ontological security. The research involves 97 students of medical college at the age of 17-21. The empirical research applied the following methods: methods of "Diagnostics of activity of students" DAS-2 (A.Yu. Popov, A.A. Volochkov); questionary of ontological security (OS-PM); method of ontological security built up on the principle of semantic differential (OS-SD) (N.V. Kopteva). As a result of empirical research, it was stated that broad-spectrum activity of students is implemented and developed in connection with one of the basic grounds of human - ontological security. Out of three model components of activity structure: need in interaction - volitional regulation of interactions satisfaction with interactions, the first two components are stronger connected with ontological security that the third component. Out of the life spheres where the activity is found, activity in communication and activity in learning have closer connections with ontological security that any other areas of life.
\end{abstract}

\section{Introduction}

Rapidly developing communication technologies lead to dramatic changes in various spheres of students' lives - their educational activities, communication and leisure, and these changes influence the activity of the subjects and catalyse mixed forms of behaviour, namely, the transition from the real world to the virtual space and back again (A.E. Voiskunsky, Yu.P. Zinchenko) [1, 2] and construction of a desired self-image (E.P. Belinskaya, A.E. Zhichkina et al.) [3,4]. Integral activity of students and its link to an ontological security remains understudied in psychological science. N.V. Kopteva supposes that under presentday conditions, due to the growth and spread of the Internet, every person has an opportunity for disembodied existence, which reasonably corresponds to the formula of schizoid existence proposed by R.D. Laing: self $\leftrightarrow$ (body-other) or self $\leftrightarrow$ (body-world) (N.V.

\footnotetext{
* Corresponding author: vasyura@inbox.ru
} 
Kopteva) [5, 6]. Thus, the problem of disembodiment of Internet user in virtual space as technological form of disengagement is becoming crucial.

The general psychological construct of ontological security proposed by N.V. Kopteva, based on R.D. Laing's concept, contains a continuum of existential positions: "ontological security, embodiment- ontological insecurity, unembodiment". Ontological security is viewed by N.V. Kopteva as one of the basic grounds of human life, as a system of experiences, relating to human experience of own self in integration with body.

The researcher identifies two levels of private emotional experiences, which are related to basic notions of security, and are expressed in a range of more specific emotional experiences:

- The level of less differentiated, basic, value-based emotional experiences - their starting point is the person's experience of their own embodied self; while these emotional experiences are not specificto the elements of being-in-the-world (the self, the body, the world, the people, the meaningful as an individual value), they invest them with a sense of existential support and combine the space of being-in-the-world into a single whole.

- The level of more differentiated emotional experiences of a person's autonomy and a simultaneous sense of being connected with other people and the world [7].

Recent years have seen the growing interest of psychologists towards the problem of human activity, forms of its manifestation and mechanisms of its performance and development, in particular, in real and virtual spaces. Psychology of activity is a new area of humanitarian and scientific research. In psychological science activity is defined as a universal way, form and measure of natural and social interactions, where a human being is developed and appears as a subject [8].

Different types of students' activity are being studied - social (R.M. Shamionov, M.V. Grigorieva, A.V. Grigoriev, N.N. Samsonova) [9, 10, 11], educational (A.A. Volochkov) [12], communicative (S. A. Vasyura, N.A. Lukina et al.) [13, 14], sense-making (A.Yu. Kalugin et al.) [15]. Attempts are being made to exercise holistic activity in various spheres of students' lives, and its relation to ontological security concept deserves careful study.

Our empirical research was aimed at studying activity in different spheres of life and students' ontological security to identify the connection between activity in communication, cognition, educational activity, contemplation, and reflection with the sense of ontological security. As a hypothesis of the study, it is suggested that activity in the field of communication and activity in educational activities have closer links with ontological security than activity in other spheres of life.

\section{Materials and methods}

The research involved 97 students aged of 17-21 from the Republican medical college of Udmurt Ministry of Healthcare.

The theoretical and methodological framework of the research project relies on the concept of the subject's activity, proposed by A.A. Volochkov, and the theoretical and empirical construct of ontological security, proposed by N.V. Kopteva, based on the approach developed by R. D. Laing. General methodological basis of the research is S.L. Rubinstein principle of unity of consciousness and activity.

Research methods and techniques:

1. Theoretical methods: the review-and-analysis method that implies theoretical analysis of monographs, dissertations, articles and other scholarly publications on the research problem.

2. Empirical methods (psychodiagnostic techniques):

a. Method of "Diagnostics of Students' Activity (DAS-2)" (A.Yu. Popov, A.A. Volochkov) includes 15 scales, matching with triple-component model of activity: 
need in interaction - volitional regulation of interactions - satisfaction with interactions in such areas of life activity as communications, experience, knowledge, learning, reflection (the method also includes such areas as information technology while describing areas of activity) [16];

b. Techniques of studying ontological security - the Ontological Security Questionnaire (OS-PM); the technique of studying ontological security based on semantic differential and evaluation of objects - elements of being-in-the-world for which a person feels a sense of security (OS-SD) (N.V. Kopteva) [12]. The OS-PM measurement technique consists of 30 points, which make up four primary scales. Three scales measure ontological security aspects: autonomy, vital contacts with the world, and vital contacts with people. The scale of "false self" characterises uncertainty and unembodiment. The integrated index of the experience of autonomy, separation from other people and the world, and a simultaneous sense of connectedness with them is calculated by adding the first three scales and subtracting the index of the "false self" scale from the sum of the first three scales.

3. Methods of mathematical data processing: quantitative methods (descriptive statistics methods, Spearman's rank correlation analysis, performed using SPSS 11.5 program for Windows).

4. The interpretive method: the structural method.

\section{Results}

Let us now turn to the results of the correlation analysis of students' activity in different spheres of life, evaluated with "Diagnostics of Students' Activity DSA-2" technique (A.Yu. Popov, A.A. Volochkov); and of ontological security, identified using the OS-PM and OSSD techniques (N.V. Kopteva) (Fig. 1).

It was found that the scale of "subjectivity of choice in communication" is positively correlated with the general index of ontological security (OS-PM) $(0.201, p=0.048)$ and with autonomy index $(0.383, \mathrm{p}=0.000)$. Positive correlation of this scale with the integrated index of ontological security (OS-SD) $(0.292, \mathrm{p}=0,004)$ and the index of security in one's mental self $(0.257, \mathrm{p}=0.011)$, security in the world $(0.270, \mathrm{p}=0.008)$, and security in the meaningful as an individual value $(0.354, \mathrm{p}=0.000)$ were also revealed.

While demonstrating significant personal agency when facing a choice, which serves as a measure of their internal determination for activity in communication, students display a marked sense of ontological security as an experience of autonomy and simultaneous connectedness with people and the world, and in particular, their security in their own autonomy is stronger. The strongeris the need for communication, the more prominent is the ontological security, perceived as the emotional experience of finding existential support within one's own self and beyond, and in particular their security in the mental self, in the world, in the meaningful as an individual value is stronger.

The scale of "subjectivity of choice in cognition" is positively correlated with the autonomy index $(0.234, \mathrm{p}=0.021)$, which is quite natural. Thus, the higher is the need for interaction in cognition, the stronger is the experience of oneself as an independent personality, capable of independent choice and embodied.

The scale of "subjectivity of choice in educational activity" positively correlates with the general index of ontological security (OS-PM) $(0.252, \mathrm{p}=0.013)$, with indices of autonomy $(0.239, \mathrm{p}=0.018)$ and vital contacts with the world (life satisfaction) $(0.304, \mathrm{p}=0.002)$. This scale reveals a positive correlation with the integrated index (OS-SD) $(0.282, \mathrm{p}=0.005)$, the index of security in the world $(0.285, \mathrm{p}=0.005)$ and the index of security in people $(0.277$, $\mathrm{p}=0.006$ ). 


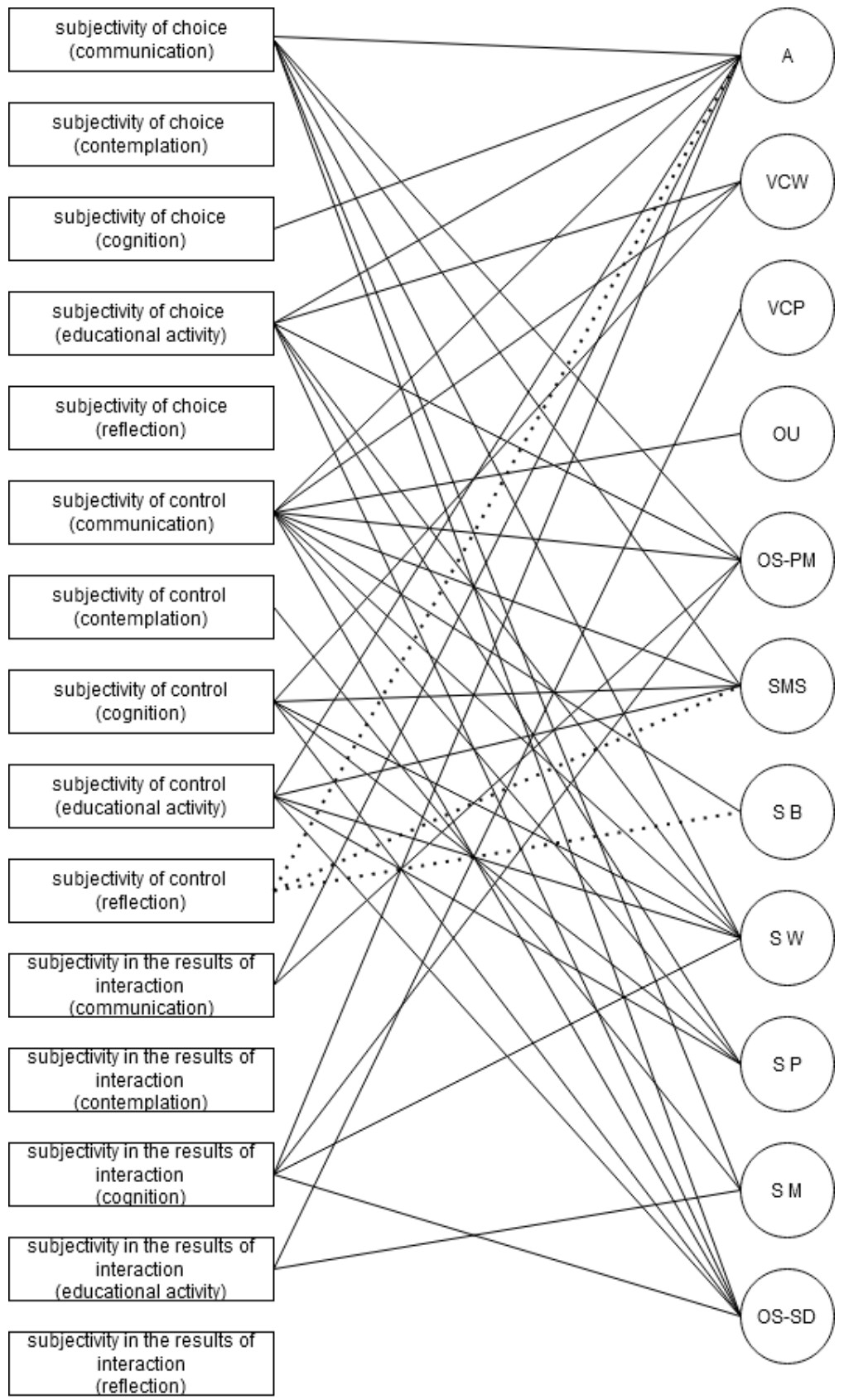

Legend: $A$ - Autonomy, $V C W$ - Vital contacts with the world, $V C P$ - Vital contacts with people, $O U$ - ontological uncertainty, $O S-P M$ - the general index of ontological security, $S M S$ - security in the mental self, $S B$ - security in the body, $S W$ - security in the world, $S P$ - security in people, $S M-$ security in the meaningful as an individual value, $O S-S D$ - the integrated index of ontological security. - positive correlation;

- - - - - - negative correlations.

Fig. 1. Graphic representation of the indicators of the DAS-2 methodology with the indicators of the ontological security methodology 
The stronger is the need for interaction in educational activity, the more prominent is the ontological security, perceived as an experience of separation from other people and the world and a simultaneous connectedness with them, and in particular, the security in personal autonomy and connections with people and the world is stronger, and the sense of life satisfaction is also stronger.

The stronger is the personal agency when facing a choice in educational activity, the more pronounced is ontological security, perceived as the emotional experience of finding existential support in one's own self and beyond, and in particular, the security in the world and in people is stronger.

It was found that the scale of "subjectivity of control in communication" positively correlates with the general index of ontological security (OS-PM) $(0.369, p=0.000)$, the autonomy index $(0.411, \mathrm{p}=0.000)$, the index of vital contacts with the world $(0.308, \mathrm{p}=0.002)$, and the index of ontological uncertainty $(0.250, \mathrm{p}=0.014)$. Positive correlations of this scale with the integrated index of ontological security (OS-SD) $(0.329, \mathrm{p}=0.001)$, index of security in the mental self $(0.372, \mathrm{p}=0.000)$, security in the body $(0.200, \mathrm{p}=0.050)$, security in the world $(0.305, \mathrm{p}=0.002)$, and security in people $(0.200, \mathrm{p}=0.049)$ were revealed.

Strengthening of the volitional regulation of interaction in communication increases ontological security at the level of experiencing autonomy and simultaneously a sense of being connected with people and the world, and in particular, it strengthens a sense of security in personal autonomy, a sense of security in one's own world as a reliable one, and also increases ontological uncertainty. The stronger is the volitional regulation of interaction in communication, the stronger is the ontological security, perceived as the experience of finding existential support in one's own self and beyond, and in particular, security in the mental self, in the body, in the world and in people is stronger. Thus, as evidenced by the results of the correlation analysis, the index of ontological security in general and of its individual components increase with the increase in volitional regulation of interaction in communication, but the false self index also increases. This result can be explained by the complexity and multidimensionality of communication as a field of the subject's activity.

The scale of "subjectivity of control in contemplation" is positively correlated with the index of security in the meaningful as an individual value $(0.216, p=0.034)$. The stronger is the volitional regulation of interaction as a measure of personal agency in the exercise of activity in contemplation, the stronger is the students' security in the significant as an individual value.

As a result of the correlation analysis, it was revealed that the scale of "personal agency in control of cognition" is positively correlated with the index of vital contacts with the world $(0.214, \mathrm{p}=0.036)$. Positive correlation of this scale with the integrated index of ontological security $(\mathrm{OS} \mathrm{SD})(0.289, \mathrm{p}=0.004)$ and indices of security in the mental self $(0.214, \mathrm{p}=0.035)$, security in the world $(0.261, \mathrm{p}=0.010)$ and security in people $(0.310, \mathrm{p}=0.002)$ were found.

The stronger is the volitional regulation of interaction in cognition, the stronger is the sense of life satisfaction and security in one's world as a reliable one. The stronger is the personal agency in control of cognition, the stronger is the ontological security, perceived as the experience of finding existential foundations in one's own self and beyond, and in particular, security in the mental self, in the world and in people is stronger.

The scale of "subjectivity of control in educational activity" reveals a positive correlation with the autonomy index $(0.283, \mathrm{p}=0.005)$. Positive correlation of this scale with the integrated index of ontological security $(\mathrm{OS}-\mathrm{SD})(0.315, \mathrm{p}=0.002)$ and indices of security in the mental self $(0.219, \mathrm{p}=0.031)$, security in the world $(0.333, \mathrm{p}=0.001)$, and security in people $(0.214, \mathrm{p}=0.035)$ were found.

Strengthening of students' personal agency in control of educational activity increases their security in their autonomy, their experiencing of themselves as independent personalities, capable of independent choice and embodied. The stronger is the volitional 
regulation of interaction in educational activity, the stronger is the ontological security, perceived as the experience of finding existential support in one's own self and beyond, and in particular, security in the mental self, in the world and in people is stronger.

The scale of "subjectivity of control in reflection" is negatively correlated with the autonomy index $(-0.277, \mathrm{p}=0.006)$. Negative correlations of this scale of activity with indices of security in one's mental self $(-0.218, \mathrm{p}=0.032)$ and confidence in one's body $(-0.262$, $\mathrm{p}=0.010$ ) were revealed.

The stronger is the volitional regulation of interaction in reflection, the lower is the security in personal autonomy, security in one's own self and in the body, and vice versa in case of low volitional regulation of reflection, these indices of ontological security are prominent.

The scale of "subjectivity of the results of interaction in communication" is positively correlated with the integrated index of ontological security $(\mathrm{OS}-\mathrm{PM})(0.243, \mathrm{p}=0.017)$ and the autonomy index $(0.333, \mathrm{p}=0.001)$.

The stronger is the satisfaction with the results of interaction in communication, the stronger is the ontological security at the level of experiencing autonomy and simultaneously being connected with people and the world, and in particular, the security in personal autonomy is stronger.

The scale of "subjectivity of the results of interaction in cognition" is positively correlated with the general index of ontological security $(\mathrm{OS}-\mathrm{PM})(0.223, \mathrm{p}=0.028)$ and the autonomy index $(0.298, p=0.003)$. Positive correlations of this scale with the integrated index of ontological security (OS-SD) $(0.233, \mathrm{p}=0.022)$ and the index of security in the world $(0.265$, $\mathrm{p}=0.009)$ were discovered.

Thus, the stronger the students' satisfaction with the results of interaction in cognition, the stronger is the ontological security, perceived as the experience of autonomy and connectedness with people and the world, and in particular, security in personal autonomy is stronger.

The stronger is the satisfaction with interaction in cognition, the stronger is the ontological security at the level of experiencing existential support in one's own self and beyond, and in particular, security in the world is stronger.

The scale of "personal agency in the results of interaction in educational activity" is positively correlated with the index of vital contacts with people $(0.290, \mathrm{p}=0,004)$ and the index of security in the meaningful as an individual value $(0.273, \mathrm{p}=0,007)$.

The stronger is the satisfaction with the results of interaction in educational activity, the stronger is the students' interest in people, their experience of themselves as being "together with other people in this world" and their security in the meaningful as an individual value.

\section{Discussion}

In general, the analysis of correlations between the indices of the subject's life activity with the indices of ontological security among students demonstrates that the greatest number of correlations (seventeen) is found in the field of communication, while the smallest number of correlations is found in the field of contemplation (one). In the field of reflection, negative correlations of indices of autonomy, security in the mental self, and security in the body, with the index of personal agency in control were revealed.

Most of the correlations (eight) of the indices of the activity of the vital activity subject were with the autonomy index. That is, autonomy corresponds to activity in communication, to an increase in the need for interaction and satisfaction with interaction in cognition, to an increase in the need for interaction and volitional regulation of interaction in educational activity and to a decrease in volitional regulation of interaction in reflection. 
All indices of activity in communication positively correlate with the integrated index of ontological security at the level of experiencing existential support in human life. Thus, the higher is the rate of the subject's activity in communication, the more pronounced are their positive temporal and spatial characteristics of being-in-the-world, their overall attitude to reality, the subject's optimistic attribution of life events, and their belief in the controllability of life as a whole.

Ontological security, and its levels taken as a united whole, is positively associated with personal agency when facing a choice, and personal agency in control of communication, personal agency in the results of interaction in cognition, and personal agency when facing a choice in educational activity. That is, the stronger is the need for interaction and volitional regulation of interaction in communication, the stronger is the satisfaction with interaction in cognition, and the stronger is the need for interaction in educational activity, the stronger is ontological security, perceived as the person's experience of the integrity of their being, a sense of belonging to the world and affiliation with other people, their experience of finding existential support in their own self and beyond, in what constitutes not-self, perceived as a "resourceful" feeling, as opposed to the experience of an alienated, false self.

Of the indices of personal agency, the indices of personal agency in contemplation, personal agency in the results of interaction in contemplation, personal agency in reflection, and personal agency in the results of interaction in reflection are not correlated with ontological security.

\section{Conclusions}

So, as a result of the empirical research the connections of student activity with ontological security were established. Broad-spectrum student activity is realized and developed relating to one of the grounds of human life - ontological security. It is stated that the out of three components of the activity structure in the model (i.e. measure of subject, showing interactions at different stages): need in interaction - volitional regulation of interactions satisfaction with interactions, the first two components demonstrate closer connection with ontological security than the third one. This component - satisfaction implies individual way out beyond the conventional and "the average" and connected not only with the results of activity but with individual efforts to overcome limitations in the interaction. Fewer connections of this component with ontological security may be explained by its complication, "two-layers".

Out of spheres of life where activity can be found, the activity in communication and activity in learning relate to ontological activity stronger than any other type of activity. Other typical for students' areas of activity - knowledge, experience, reflection - have fewer connections with ontological security. Subject option in reflection as a student need in independent time organization to do reflection to self and own place in the world shows no connections with ontological security and its forms.

The research has a practical importance for experts of psychological services in educational institutions while they provide individual consultations and psychological awareness. The research findings may be of interest to university teachers, tutors and curators.

\section{References}

1. A.E. Voiskunskiy, South-Russian Journal of Social Sciences 4, 21-39 (2019).

2. Yu.P. Zinchenko, The Psychology of Virtual Reality, Monograph. Lomonosov Moscow State University, Moscow (2011). 
3. E.P. Belinskaya, O.V. Gavrichenko, Psychological Studies 11 (60), 12 (2018).

4. A.E. Zhichkina, Psychological Journal 21(2), 75-78 (2000).

5. R.D. Laing, The Divided Self (White Rabbit, Saint Petersburg, 1995).

6. N.V. Kopteva, Journal of Ural University Problems of education, science and culture 1 (71), 118-126 (2010).

7. N.V. Kopteva, Siberian Psychological Journal 65, 6-21 (2017).

8. A.A. Volochkov, Activity of the subject of being: integrative approach, Perm State University of the Humanities and Pedagogy, Perm (2007).

9. R.M., Shamionov, M.V.Grigorieva, Psychology of social activity of youth: problems and risks, Saratov University press, Saratov (2012).

10. R.M., Shamionov, M.V.Grigorieva, A.V. Grigoriev, Social psychology and society 1, 18-34 (2019).

11. N.N. Samsonova, The Relation between Internet Communication and Social Behavior of Young People, Extended abstract of Candidate of Psychological Sciences dissertation Moscow (2018).

12. A.A. Volochkov, Activity, Value Orientation and Psychological Health of Students, Perm State University of the Humanities and Pedagogy, Perm (2016).

13. S.A. Vasyura, Izvestiya of Saratov University 1 (33), 77-84 (2020).

14. N.A. Lukina, Psychological Features of Students' Internet-Mediated Interpersonal Communication, Extended abstract of Candidate of Psychological Sciences dissertation. Samara (2013).

15. A.Yu. Kalugin, Bulletin of Perm University 4 (20), 46-52 (2014).

16. A.Yu. Popov, A.A. Volochkov, Structure and psychological diagnostics of student activity, Perm, Perm State Humanitarian Pedagogical University (2015). 